\title{
STUDIES ON AMMONIFICATION IN SOILS BY PURE CULTURES
}

\author{
BY \\ C. B. LIPMAN AND P. S. BURGESS
}

The study of the physiological efficiency of soil bacteria rather than their number is admittedly the dominant method in soil bacteriological investigations. In view of this fact it is singularly striking to note how little work has been accomplished in the study of some phases of the physiological efficiency of pure cultures of certain groups of soil bacteria. This is especially so, since the introduction of radical changes in our soil bacteriological methods have made it necessary to repeat some, if not all, of the work which had been carried out by the old methods. However this may be, it remains a fact that, since the publication of Marchal's ${ }^{1}$ splendid work on ammonification in solution cultures, but scant information has been adduced from studies of soil bacteria which relate to the physiology as well as the physiological efficiency of even the more common ammonifying bacteria. Certainly, the work carried out along this line in direct soil cultures, which recent work has shown to be so far superior to solution cultures, has been very meager indeed.

In order, therefore, to glean some useful information relative to the physiological efficiency of pure cultures of a number of ammonia-producing bacteria, the writers deemed it wise to select a number of organisms and to compare their power to produce ammonia not only from one form of organic matter, but from several forms, most of which have found use in farm practice as fertilizers. Accordingly, the following organisms in pure 
culture were selected for the experiments: B. mesentericus vulgatus, Ps. putida, B. vulgatus, B. megatherium, B. mycoides, B. subtilis, B. tumescens, Sarcina lutea, B. proteus vulgaris, $B$. icteroides, B. ramosus, Streptothrix, sp., Ps. fuorescens, B. vulgaris (Novy strain), Mic. tetragenus. The organic materials experimented with were dried blood $(13.16 \% \mathrm{~N})$, tankage $(9.62 \% \mathrm{~N})$, cottonseed meal $(5.5 \% \mathrm{~N})$, sheep and goat manure $(2.13 \% \mathrm{~N})$, peptone $(14.14 \% \mathrm{~N})$, fish guano $(8.63 \% \mathrm{~N})$, and bat guano $(3.96 \% \mathrm{~N})$.

\section{Method of Experiments}

Fifty-gram portions of soil were placed in tumblers and thoroughly mixed with the organic material to be tested. The tumblers were covered with Petri dish covers and sterilized in the antoclave at a pressure of thirty pounds for three hours. After cooling, the soils were each inoculated with a 1 cc. suspension of the organisms to be tested, made up by shaking with some sterile water a young slope culture grown on bouillon agar. The soil was then stirred with a sterile spatula after enough sterile water had been added to make a moisture content in the soil about equal to the optimum. The soil cultures thus prepared were incubated at $28^{\circ}$ to $30^{\circ} \mathrm{C}$ for twelve days. After the incubation period the soils were transferred to copper distilling flasks, $400 \mathrm{cc}$. of distilled water and an excess of $\mathrm{Mg} \mathrm{O}$ added, and distilled into standard $\mathrm{H} / 10 \mathrm{HCl}$. The ammonia was then determined in the usual way.

No attempt was made to run all the series with the different forms or organic matter at the same time, because only the relative powers of the different organisms to produce ammonia were sought. For the same reason amounts of organic matter were chosen in the different series which would least affect the physical conditions obtaining in the cultures rather than amounts employed which would make the total amount of nitrogen added the same in all series.

For the reasons above given, therefore, the effects of the various organisms on any given form of organic material will be treated below as a separate series in the case of each soil and 
comparisons between the different series made only where permissible. The data, moreover, are presented so that the duplicate determinations which were carried out in all cases may be compared. The averages of duplicate determinations, however, are also given as well as the percentages of nitrogen in the organic matter which was transformed to ammonia.

Three different California soils were tested with each one of the ammonifiable materials. The soils were a sandy soil from Anaheim, a clay loam from Davis, and a black clay-adobe soil from Berkeley. The mechanical and chemical analyses of these soils are given in Tables I and II which follow.

\section{TABLE I}

Mechanical Analyses of Solls

$\begin{array}{lrcc}\text { Hyd. value } & \text { Sandy } & \text { Clay-Loam } & \text { Clay-Adobe } \\ \text { Clay } & 5.78 & 19.12 & 31.93 \\ 0.25 \mathrm{~mm} . & 14.59 & 40.93 & 25.77 \\ 0.50 & 1.04 & 3.35 & 3.40 \\ 1 & 2.30 & 6.60 & 4.77 \\ 2 & 5.28 & 7.75 & 7.49 \\ 4 & 9.62 & 8.78 & 6.20 \\ 8 & 11.58 & 8.10 & .87 \\ 16 & 4.87 & 3.30 & 2.78 \\ 32 & 15.23 & 4.15 & 7.66 \\ 64 & 29.40 & 3.07 & 5.44\end{array}$

TABLE II

Chemical Analysis of Soils

\begin{tabular}{|c|c|c|c|}
\hline & Sandy & Clay-Loam & Clay-Adobe \\
\hline Insoluble matter & 73.59 & 53.55 & \\
\hline Soluble silica & 11.17 & 19.77 & 77.84 \\
\hline $\mathrm{K}_{2} \mathrm{O}$ & .64 & .75 & .45 \\
\hline $\mathrm{Na}_{2} \mathrm{O}$ & .15 & .11 & .07 \\
\hline $\mathrm{CaO}$ & 1.39 & .82 & 1.05 \\
\hline $\mathrm{MgO}$ & .93 & 1.39 & 1.21 \\
\hline $\mathrm{Mn}_{3} \mathrm{O}_{4}$ & .04 & .04 & .08 \\
\hline $\mathrm{Fe}_{2} \mathrm{O}_{3}$ & 5.10 & 7.56 & 4.68 \\
\hline $\mathrm{Al}_{2} \mathrm{O}_{3}$ & 3.92 & 10.04 & 7.79 \\
\hline $\mathrm{P}_{2} \mathrm{O}_{5}$ & .12 & .13 & .23 \\
\hline $\mathrm{SO}_{3}$ & .02 & .03 & .08 \\
\hline $\begin{array}{l}\text { Water and } \\
\text { organic matter }\end{array}$ & 2.88 & 5.62 & 5.72 \\
\hline
\end{tabular}


The pure cultures of the organisms employed in these investigations were obtained by one of us from the bacteriological laboratories of the University of Illinois. Fresh strains of $B$. subtilis and B. mycoides were, however, isolated by us from California soils in order to check the stock cultures of the same organisms. The same relative powers of producing ammonia were, however, found to obtain with the fresh as with the old, and different strains thus strengthening the validity of the results below discussed.

\section{Series I. Experiments with Dried Blood}

\section{Sandy Soil}

Two per cent of finely sifted dried blood was added to the soils in this series, or one gram per fifty grams of soil. In the case of the sandy soil three series in duplicate were tried, and the same relation under different conditions having been found to obtain between the ammonifying powers of the different organisms, we give only one duplicate set of the determinations. The incubation period was twelve days throughout at a temperature varying between $27^{\circ} \mathrm{C}$ and $30^{\circ} \mathrm{C}$. The results of the ammonification determinations with all the soils using dried blood throughout are given in Table III. The percentage of nitrogen of the total amount added which is made available is also given in every case.

The data in Table III most strikingly indicate the superiority of Ps. putida, B. vulgaris and Sarcina lutea to all other organisms in their efficiency at the production of ammonia from the nitrogen of dried blood. The next fact of singular interest is that $B$. mycoides, which has, in the hands of several investigators, shown such marked superiority over other ammonifying organisms in the production of ammonia from organic nitrogen in solutions, manifests a relatively low power to transform the nitrogen of dried blood in soil cultures into ammonia. This, moreover, cannot be considered accidental, since different strains of $B$. mycoides, as above explained, exhibited that same lack of vigor in three duplicate sets of eultures run at different times and under slightly varying conditions of temperature and period of incuba- 


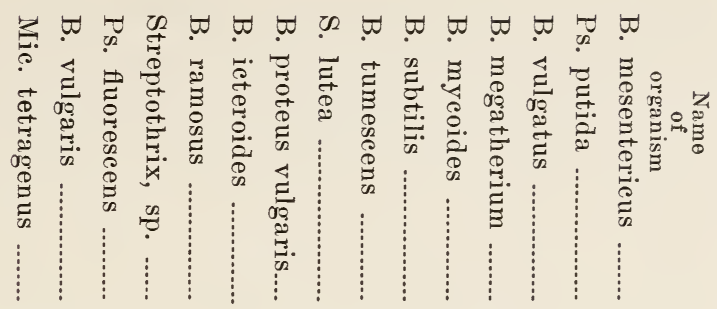

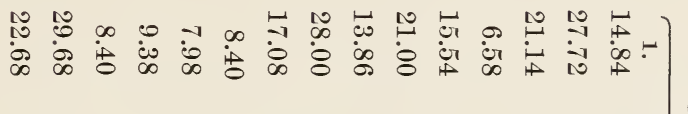

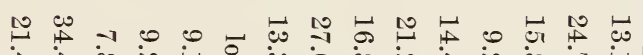

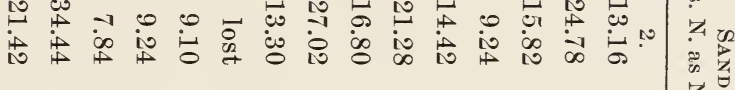

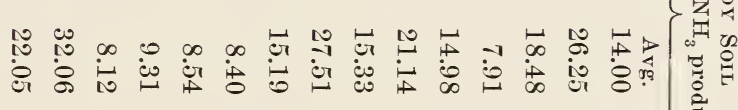

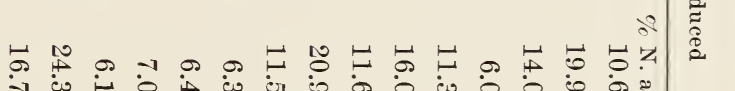

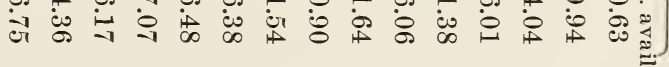

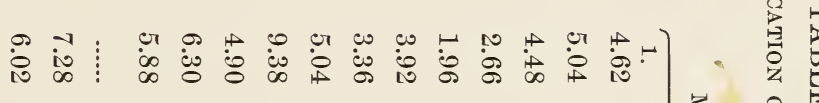

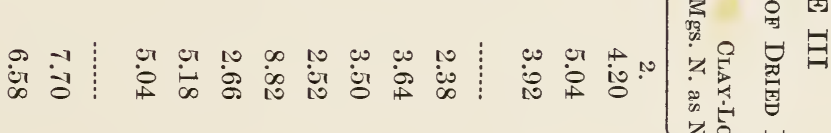

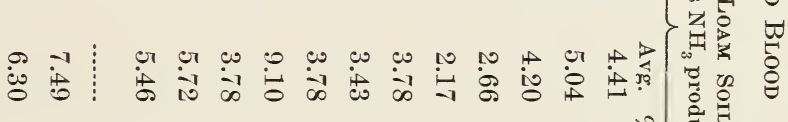

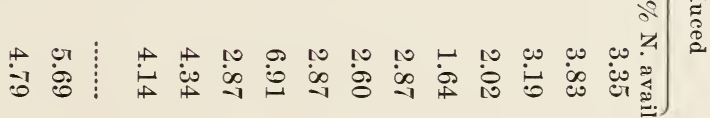

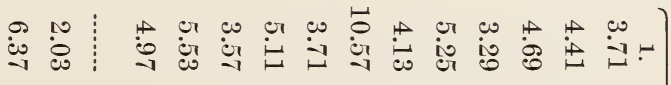

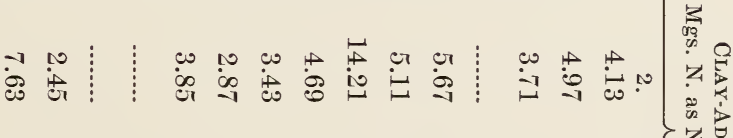

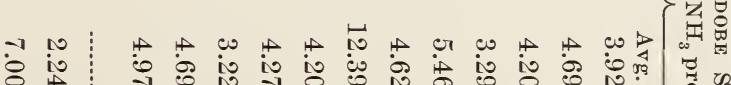

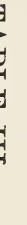


tion. Of the three organisms showing the highest efficiency, as above indicated, in transforming the nitrogen of dried blood to ammonia, B. vulgaris appears in its turn to be the most vigorous, though the other two approach it closely and are about equal among themselves.

\section{Clay-Loam Soil}

When the clay-loam soil is used as the medium with dried blood, marked differences are apparent in the efficiency of all the organisms. The poorer air supply of the clay-loam soil, due to its fineness and much greater tenacity, are evidently inimical to ammonia production, even though the same source of nitrogen -dried blood-is supplied for the ammonification process. The largest amount of ammonia produced in this series was that by $B$. proteus vulgaris, and even that was little more than one quarter of the amount produced by $B$. vulgaris as above noted in the sandy soil.

Moreover, the most efficient transformers of the nitrogen in dried blood in the sandy soil medium are not necessarily the same as those in the clay-loam soil. For example, in the case of the clay-loam soil $B$. proteus vulgaris is the most efficient ammonia producer with dried blood as ammonifiable material, while in the sandy soil the same organism manifests less than half the ammonifying efficiency of $B$. vulgaris. This latter organism, however, stands second to $B$. proteus vulgaris in efficiency in the clay-loam soil and yields $7.49 \mathrm{mgs}$. of ammonia nitrogen as against $9.10 \mathrm{mgs}$. produced by the last-named organism. There appear to be four other organisms which approach the efficiency of the two just discussed in the clay-loam soil in the following order: Wic. tetragenus, B. ramosus, Streptothrix, sp., and Ps. putida. While the latter does not compare in efficiency in the clay-loam soil with that shown by it in the sandy soil, it still manifests a notable efficiency. Sarcina lutea, however, appears to have lost in the clay-loam soil the marked ammonifying power possessed by it in the sandy soil.

Of course it must be again emphasized that the amounts of ammonia produced by all the organisms in the clay-loam soil 
series are relatively so small that the margin allowable for safe comparison must of necessity be much decreased and therefore comparisons are more difficult.

\section{Clay-Adobe Soll}

Passing on to a study of the data obtained with the clay-adobe soil as a medium, we find again that he physical condition of the soil is a powerful factor in determining the amount of ammonia produced in soils by pure eultures of organisms possessed of ammonifying powers, if the fifteen different organisms used are a suitable criterion. This confirms the findings of J. G. Lipman in his long series of ammonification experiments with mixed cultures. For practical purposes, we may add that most of the bacteria ammonify dried-blood nitrogen equally well in the clayadobe soil and in clay-loam soil, though there does appear to be a slight though consistently greater amount of ammonia produced in the first-named soil. Again, we find in the clay-adobe soil an organism which stands out as far superior to all others in ammonifying efficiency and again also it is not the same organism as manifested that superiority in the preceding soil. While the duplicate determinations here do not agree as well as might be desired, they indicate amounts so much greater than the quantities of ammonia produced by the other organisms of the series that there can be no doubt of the marked and superior efficiency of $B$. tumescens as an ammonia producer from the nitrogen of dried blood in the clay adobe soil as a medium. Two other organisms appear to be in the second class in this series and they are Mic. tetragenus and B. mycoides. The first, it can be seen from Table III, occupied third place in efficiency in the clay loam soil, but the second has thus far been relatively inefficient. All the other organisms of the series do not manifest differences in efficiency of sufficient magnitude to warrant further comment. except that it is curious and interesting to note that the most efficient organism in the sandy soil is the least efficient organism in the adobe soil.

It should be remarked here that the generally excellent agreement between duplicate determinations, as slown in the table, 
eliminates the fear that physical conditions in the individual cultures might operate to produce the rather marked effects noted.

In a comparison of the three soils it appears that the following organisms are among those which show the highest efficiency in transforming the nitrogen of dried blood into ammonia: Ps. putida, Sarcina lutea, B. vulgaris, B. proteus vulgaris, Mic. tetragenus, B. tumescens. Of these organisms only Mic. tetragemus shows a high efficiency in all three soils. Of the others B. vulgaris shows a high efficiency in both the sandy and adobe soils and Ps. putida in the sandy and clay-loam soil. The rest namely Sarcina lutea, B. proteus vulgaris and B. tumescens, are markedly efficient only in one soil each, namely, the sandy soil for the first, the clay-loam soil for the second, and the clay-adobe soil for the third. It appears to us particularly worthy of note, also, that of the last three organisms named $B$. proteus vulgaris and $B$. tumescens each holds a pre-eminent position of efficiency in its own soil which no other organism of the fifteen has approached; and even in the case of Sarcina lutea we find that it occupies a position in efficiency in its favorite soil which is second only to that of $B$. vulgaris and not very far behind the latter. This rather remarkable condition would hardly seem to be accidental and appears to us to indicate for certain organisms marked preferences for certain physical characteristics in media in which they are grown.

It must be added here, too, that only six of the fifteen organisms show marked ammonifying efficiency as regards the nitrogen of dried blood even when tested in three widely different soil types. The others vary but little from one another in all soils. Oddly enough, the organism which has shown the highest ammonifying efficiency because it maintained it through all soils, namely, Mic. tetragenus, has never before been looked upon, so far as we are aware, as an important ammonifier. That it should be the only one of fifteen organisms tested which should be about equally efficient in all soils used is not unworthy of note.

It is further significant to note here that $B$. mycoides, which has always been regarded as one of the most efficient soil organisms at ammonification, does not in our experiments show any unusual activity in that direction, at any rate when dried blood 
is used as the ammonifiable material, no matter what the soil medium. A possible exception to this statement may be found in the case of the adobe soil, in which $B$. mycoides seems to be superior to all but three or four of the fifteen organisms tested. Such superiority, under the circumstances noted, is probably of little significance.

\section{Series II. Experiments with Thnknge}

This series was arranged in a manner similar to the preceding, the sandy, clay loam, and clay-adobe soils again being used as media, but the ammonifiable material in this case was a highgrade tankage, the nitrogen content of which was 9.62 per cent. The results of the ammonia determinations were as shown in Table IV on page 150 .

\section{Discussion of Series II}

\section{The Sandy Soil}

When we study in the foregoing table, the ammonification of tankage by pure cultures of bacteria, and compare the results with those of Table III, we see at once some very striking differences between the ability of the same micro-organisms to produce ammonia from tankage and from dried blood respectively. Not only do more of the organisms show a high efficiency in transforming the tankage nitrogen to ammonia, but the point of highest efficiency is not reached by the same organisms as before, others having taken their places in this series with sandy soil as the culture medium. For example, we find that B. mesentericus, which in the preceding series showed throughout an extremely low ammonifying efficiency even in the sandy soil, now manifests in the same culture medium, which, however, has tankage in place of blood added to it, the highest efficiency of all of the organisms tested. Indeed, it occupies a position of its own in that direction, much as does $B$. vulgaris in the sandy soil of the last series. The organism which approaches it most closely in the same medium is $B$. proteus vulgaris which, however, falls 25 per cent short of producing the amount of ammonia yielded by 


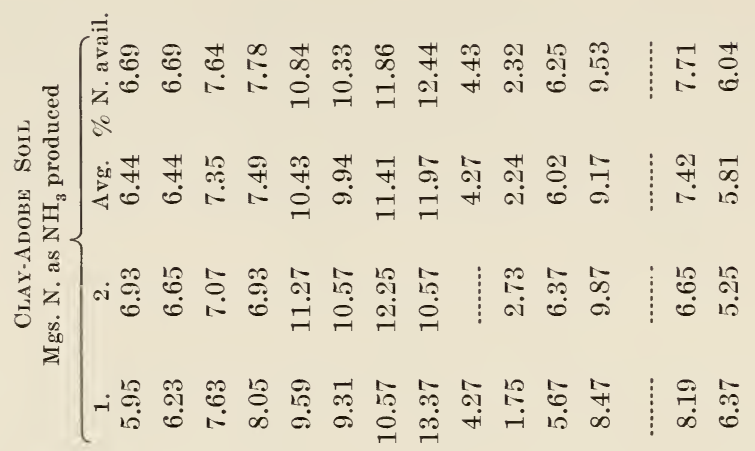
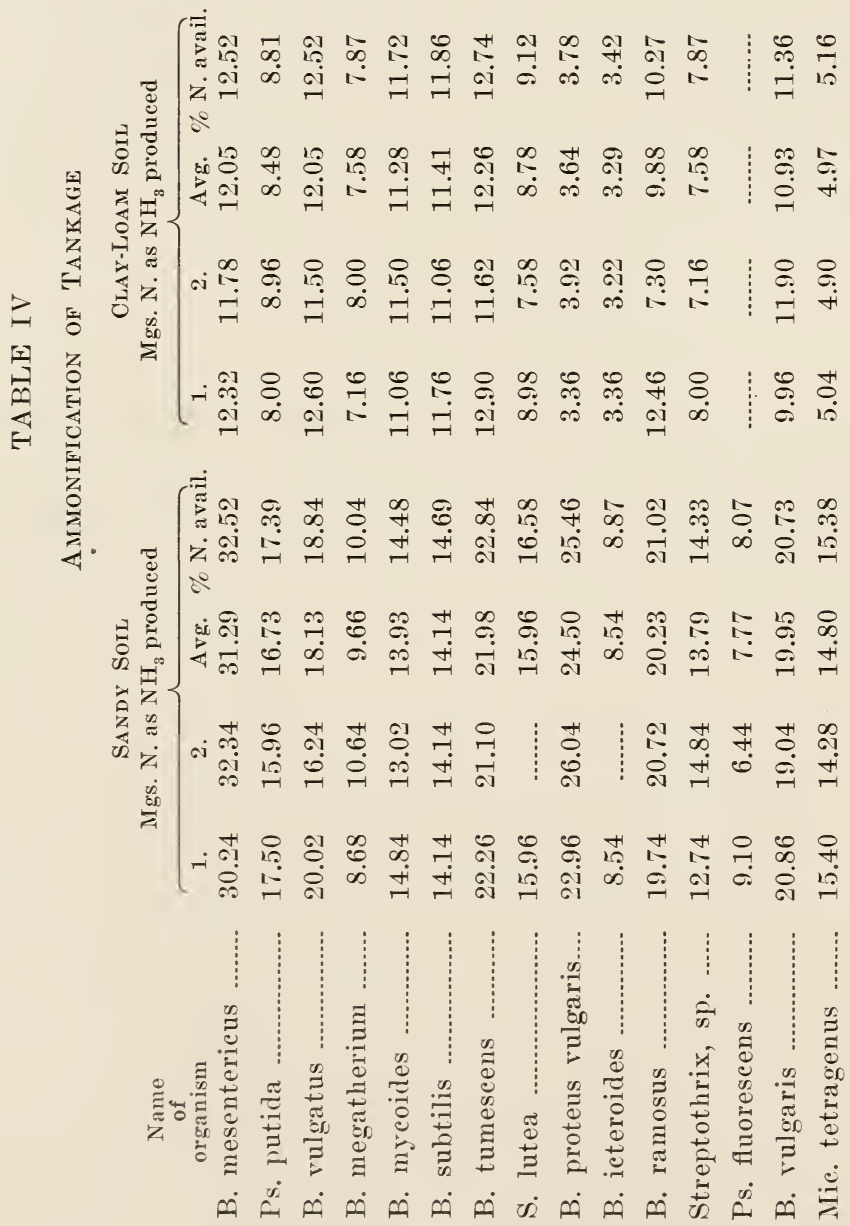
B. mesentericus. Then follow, not far behind $B$. proteus vulgaris, B. tumescens, B. ramosus, and B. vulgaris in the order named, the latter being more than $331 / 3$ per cent short of the efficiency exhibited by $B$. mesentericus. Nearly all of the other organisms fall more than 50 per cent short of the efficiency of the lastnamed organism under this set of circumstances, namely, sandy soil with tankage. There are, therefore, but five organisms out of the fifteen tested which can be adjudged distinctly efficient ammonifying organisms under these conditions. B. mycoides again exhibits a low efficiency, and not far different from, though slightly below, that manifested by it in the same soil in the driedblood series.

It must be added here that, with the exception of $B$. mesentericus, the efficient organisms in this part of Series II have also shown more or less marked efficiency in the preceding series.

\section{The Clay-Loam Soil}

Most of the organisms tested in the clay-loam soil seem to have found the latter a more congenial medium for ammonification with tankage than they did when dried blood was present. In this part of Series II, three of the organisms, namely, $B$. mesentericus, B. vulgatus, and $B$. tumescens, were not only the most efficient ammonifiers but also about equal in their ammonifying power. It appears, therefore, that so far as tankage is concerned B. mescntericus is an equally efficient ammonifier in the clay-loam and sandy soils. B. tumescens has previously established its pre-eminent position among the fifteen organisms as an ammonifier of dried-blood nitrogen in the adobe soil, but B. vulgatus enters here for the first time as a markedly efficient ammonifier.

Only slightly behind the three organisms just discussed in their ammonifying efficiency as regards tankage nitrogen in the clay-loam soil are, in the order named, B. subtilis, B. mycoides, and $B$. vulgaris. While the latter has manifested its high efficiency in other series above described, the first two organisms named for the first time in the work thus far described show marked ammonifying ability. Only three organisms in this part 
of Series II have shown themselves to be really weak ammonifiers, and they are $B$. proteus vulgaris, B. icteroides, and Mic. tetragenus. The first and the third of these, it will be remembered, have given evidence of marked efficiency under other circumstances, but the second has thus far been throughout an organism of low efficiency. It is striking to note the much greater uniformity which exists in this portion of Series II in the ammonifying powers of four-fifths of the organisms tested than that which obtains in other parts of this series and of other series.

\section{The Clay-Adobe Soil}

Here again we find the great uniformity in ammonifying power between the larger number of bacteria tester which is characteristic of the foregoing section of Series II. On the other hand, the clay-loam soil seems to have been a more congenial medium than the adobe soil for the ammonification of tankage nitrogen, for larger amounts of ammonia are produced in it by the same organisms in the same period of incubation.

Sarcina lutea shows the highest efficiency as an ammonifier in this part of the series, but is only slightly more efficient than B. tumescens. The organism taking third place is B. mycoides which, indeed, is not far behind the other two. Next in order of importance and still very efficient ammonifiers are $B$. subtilis and Streptothrix, sp. The other organisms are considerably weaker ammonifiers than those just mentioned and $B$. icteroides again proves to be distinctly the weakest. Both Sarcina lutea and B. tumescens have, as mentioned above under other circumstances, plainly evidenced their high efficiency as ammonifiers and B. mycoides and B. subtilis have taken similar positions with respect to tankage in the clay-loam soil. Streptothrix, sp., it will be remembered, has also shown a high ammonifying power before in the case of the clay-loam soil when dried blood was used.

Comparing the three soils in this series with the same ones in the preceling series, it appears quite clear that taking them hy and large, ammonifying bacteria manifest a much higher efficiency with high-grade tankage than with dried blood under similar conditions. Likewise also, in Series II a small number of 
organisms mostly identical with those in Series I seem to manifest a distinctly high efficiency which the much larger number of the balance do not in most cases even approach. It is worthy of remark, moreover, that $B$. mycoides attains or rather approaches in portions of Series II its position of prime importance which has thus far so generally been accorded it among ammonifying organisms.

\section{Series III. Cottonseed MenL}

The cottonseed meal used in this series showed on analysis a nitrogen content equal to 5.5 per cent. The experiment in this series was otherwise conducted like those of Series I and II, 2 per cent of cottonseed meal being used, or 1 gram per 50 grams of soil. The results are shown in Table III.

Again the efficiency of the organisms tested is much greater in the sandy soil than in either the clay-loam or adobe soils.

\section{Sandy Soil}

In this part of Series III the organism of greatest ammonifying efficiency is $B$. tumescens. Those approaching it closely in efficiency are B. vulgatus, Sarcina lutea, and B. mycoides in the order named. B. ramosus takes fifth place and the next three organisms fall more than $331 / 3$ per cent short of producing the amount of ammonia yielded by $B$. tumescens. They are $B$. mesentericus, B. megatherium, and B. proteus vulgaris. The balance of the organisms show only about half the efficiency of $B$. tumescens and in one case, $B$. icteroides, which has in all previous series shown a very low efficiency, only about 25 per cent of the maximum efficiency is manifested. Taken as a whole, the data given in Table III for the Anaheim sandy soil reflects favorably on cottonseed meal as a source of available nitrogen under the conditions named. Again, the greatest efficiency is manifested in this section of Series III by organisms which in all cases have shown high efficiency in other series above reported. As in the case of the heavy soil in the preceding series with tankage, B. mycoides also shows marked efficiency in the light soil when cottonseed meal is used. 


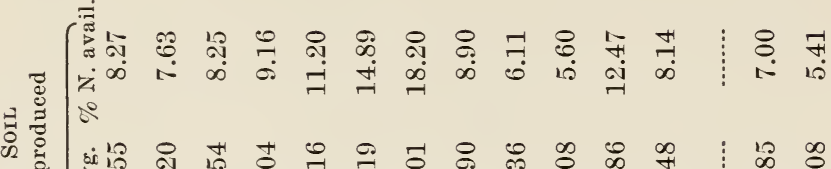

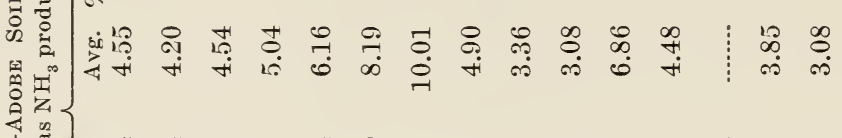

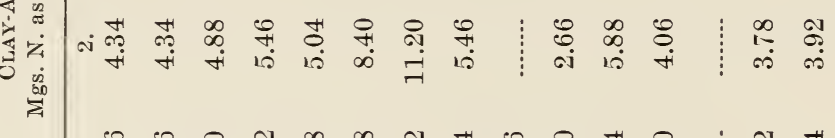

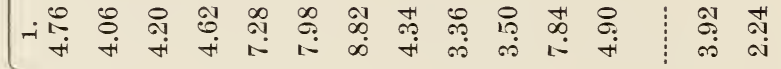

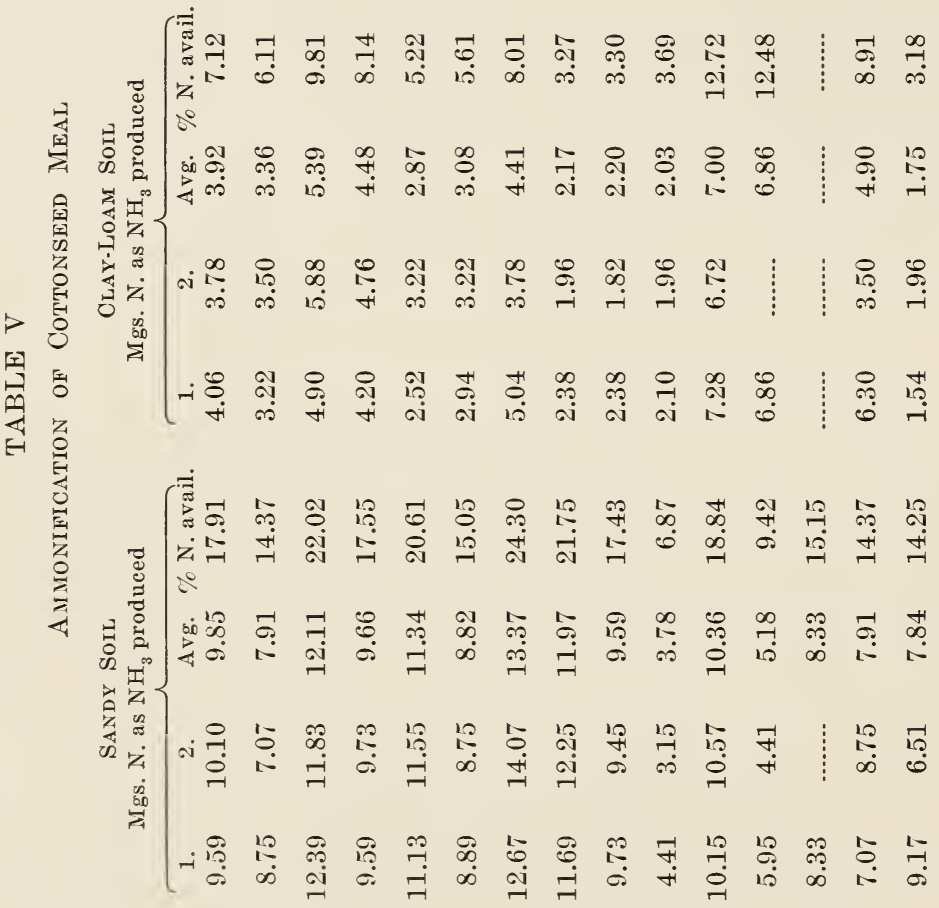

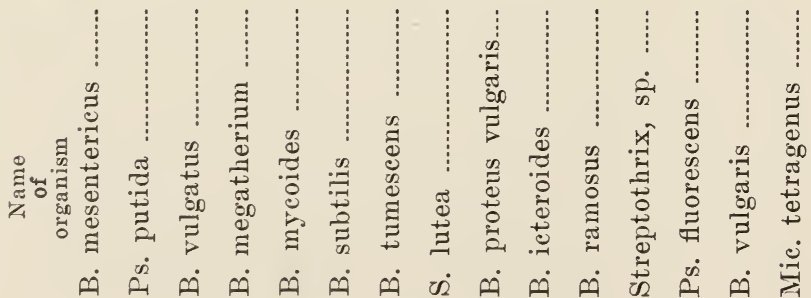




\section{The Clay-Loam Soil}

The most notable thing in this part of Series III is as above intimated, the very low efficiency of all of the organisms tested. Indeed only two organisms manifest any notable activity as ammonifiers of nitrogen in cottonseed meal in the clay-loam soil as a medium. These two in the order of their importance are B. ramosus and Streptothrix, sp. To these, in view of the disagreement of the duplicates as above shown, B. vulgaris may probably be added, and perhaps also $B$. vulgatus. The other organisms are all distinctly below the first two mentioned, and the lowest efficiency thus far noted is that exhibited by Mic. tetragemus in this soil. Considering the high efficiency of the latter organism in Series I, the results just discussed are puzzling.

\section{The Clay-Adobe Soil}

Even a casual glance at the data obtained in the clay-adobe soil as a medium indicates the distinct superiority of that medium to the clay loam soil for ammonification of the nitrogen of cottonseed meal. Not only relatively but absolutely the data obtained show the production of much larger amounts of ammonia in this portion of the work.

As is the case in the sandy soil with cottonseed meal as the ammonifiable material, B. tumescens shows its distinct superiority to the other organisms as an ammonifier in the adobe soil. The next most efficient organism is B. subtilis, which, however, is considerably less efficient; and the next two organisms, about as far below $B$. subtilis in efficiency as the latter is below $B$. tumescens, are $B$. ramosus and $B$. mycoides. The other organisms are all low in efficiency, though in nearly all cases absolutely better than the same organisms in the clay-loam soil. Thus far we find that B. subtilis shows itself markedly efficient, for the first time, in the clay-adobe soil with cottonseed meal. All the other organisms above named have manifested marked efficiency in some parts of the foregoing series.

Looking at Series III as a whole it is interesting to note that the nitrogen of cottonseed meal seems to be made available through the activity of pure cultures of ammonifying bacteria, 
with much greater rapidity than has heretofore been believed. The next striking fact brought out in these results is the clearly indicated superiority of the clay-adobe soil to the clay-loam soil as a medium for the ammonification of the nitrogen in cottonseed meal. The third point worthy of mention in Series III is the fact that we find again in it, as in the preceding series, only a few of the fifteen organisms tested which show marked ammonifying efficiency.

The culture of Ps. fuorescens died in the midst of these investigations and was not replaced.

\section{Series IV. Fish GunNo}

Fish guano, in accordance with the teachings of Voorhees and other agricultural chemists, has always been esteemed a good source of available nitrogen; in the words of Voorhees, ${ }^{2}$ " ranking in availability well up to blood and tankage." It seemed to us therefore of importance to compare in these pure culture studies fish guano with the other organic materials discussed above. Accordingly a series was started similar to those above described, except that $11 / 2$ grams of finely sifted fish guano was the ammonifiable material used per 50 grams of soil. The fish guano used contained 8.63 per cent nitrogen. The results obtained are shown in Table VI.

The data in Table VI not only seem to confirm the opinion of Voorhees as above stated, if ammonia production by pure cultures may be taken as a criterion for determining the availability of fish guano, but they indicate in most striking fashion what was not shown in any of the foregoing series for the fertilizers, and particularly in the sandy soil, namely, the obliteration of the marked physiological differences obtaining in other series between the different organisms. Of the four nitrogenous fertilizers thus far discussed, fish guano seems to contain the form of nitrogen most generally ammonified by a large group of bacteria. 


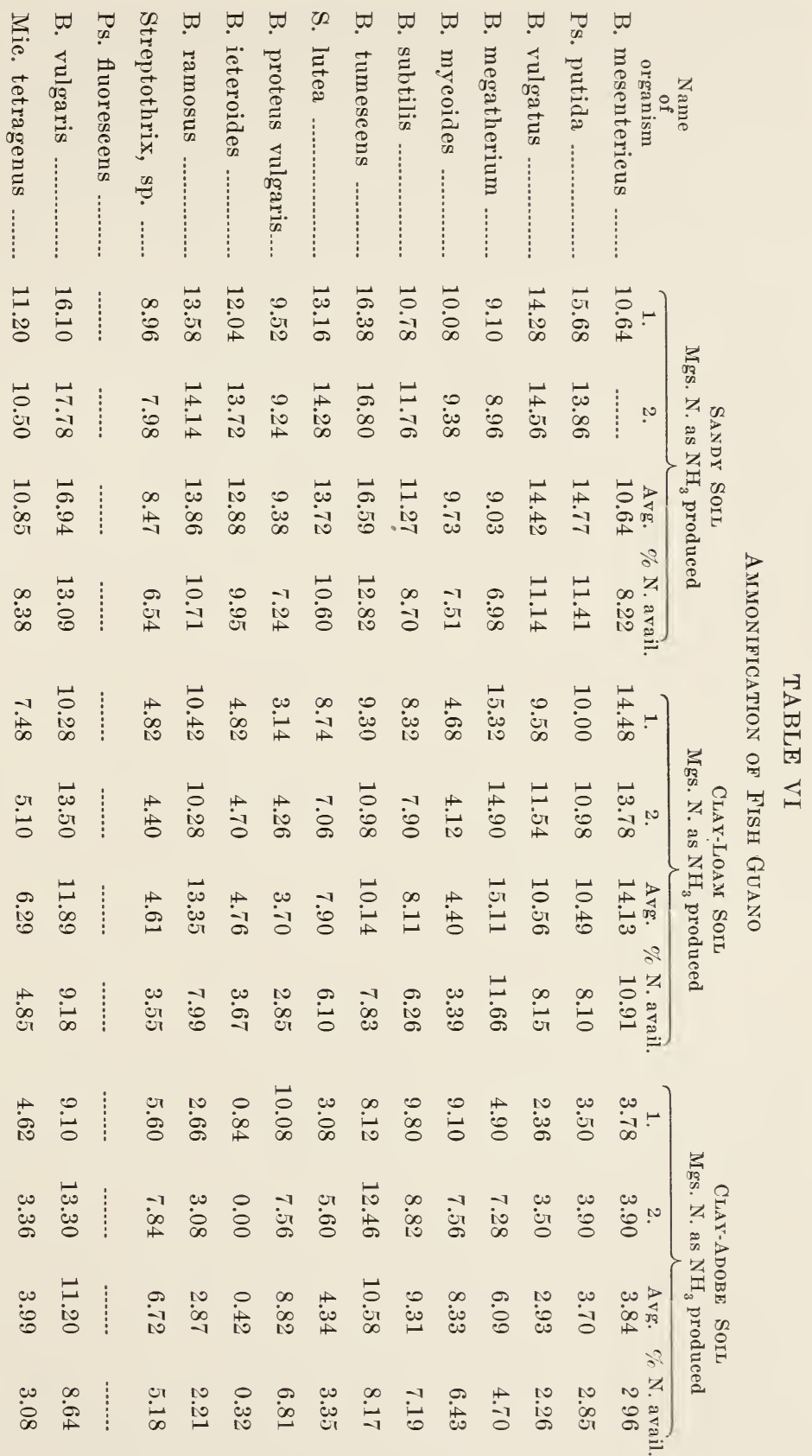




\section{The Sandy Soil}

The good ammonifying power manifested by most of the organisms tested in this soil with fish guano finds its maximum in the case of $B$. vulgaris, which, it will be remembered, has already given evidence of notable ammonifying efficiency with other nitrogenous fertilizers. $B$. tumescens, likewise an organism with a record as an ammonifier well established, is a very close second to B. vulgaris in its efficiency at the ammonification of the nitrogen in fish guano. Four other organisms distinctly in the second class, and about alike in ammonifying efficiency in this part of Series IV, are, in the order of their efficiency, Ps. putida, B. vulgatus, B. ramosus, and Sarcina lutea. Peculiarly enough, $B$. icteroides shows an ammonifying efficiency here which places it in the second class, a position which it has thus far never even remotely approached in the series of experiments above discussed, nor, for that matter, in other series which are described below. All other organisms in this part of Series IV are distinctly in the third class, but nevertheles manifest notable ammonifying efficiency.

In no other series of results have we obtained such sharp lines of demarcation between the classes of organisms here tested, and arbitrarily grouped, in accordance with their respective powers of transforming organic nitrogen into ammonia.

\section{The Clay-Loam Soil}

The change in the physical condition of the soil from the sand to the clay loam shows a marked effect on the ammonifying power of the same organisms. Nevertheless we find, on the whole, the best set of results thus far obtained with the clay loam when the series with fish guano is studied. In a class by itself under these conditions is $B$. megatherium, which is markedly superior to all other organisms in this part of Series IV, except $B$. mesentericus, which is a close second. The organism, however, which takes third place, B. vulgaris, falls about 20 per cent short of attaining the efficiency of $\boldsymbol{B}$. megatherium under these conditions. Distinctly lower in efficiency in this part of Series IV are, in the order of their importance, but only slightly different from 
one another, $B$. vulgatus, Ps. putida, B. ramosus, and B. tumescens. All of these, however, fall more than 30 per cent short of attaining the ammonifying efficiency of $B$. megatherium under the conditions here considered. Two other organisms, B. subtilis and Sarcina lutea, fall 40 per cent short of the efficiency of $B$. megatherium, and the others all fall far below even that figure.

It is singular, here again, that the physical nature of the soil medium employed should so strikingly and so variously influence the efficiency of the ammonifying bacteria. The two organisms which are distinctly superior in ammonifying ability as regards the nitrogen of fish guano in the clay loam soil were only of moderate efficiency with the same form of nitrogen in the sandy soil. And again, the organism which in the latter soil was paramount in its position retreats in the clay-loam soil to third place.

\section{The Clay-Adobe Soil}

This is the first series of those we have thus far considered, as the data in Table VI shows, in which the clay-adobe soil proves, on the whole, to be inferior to the clay-loam soil. Seven organisms out of fourteen here show an extremely low ammonifying efficiency, and two others are by no means efficient organisms. That leaves five organisms in this group which may be considered of importance. Of these, B. vulgaris is the most efficient, but $B$. tumescens is not far behind it. B. subtilis belongs to the second class in this group and $B$. proteus vulgaris and $B$. mycoides to the third class. It is rather unfortunate that it was not possible in this part of Series IV to obtain better agreement between duplicate determinations. It would not appear to us, however, that the discrepancies in question militate against the justice of the conclusions above drawn.

B. megatherium holds a very good place in the sandy and clay loam soils of Series IV and a fair place in the adobe soil. The same is even more strikingly true of $B$. vulgaris, and in a minor degree this is also true of $B$. tumescens. The other organisms do not manifest such consistent efficiency under the three widely varying soil conditions. 


\section{Miscellaneous Series}

For the purpose of comparing sheep and goat manure as well as phosphatic guano with the other organic materials above described and with peptone, it was deemed of interest to obtain data exemplifying the ammonification in the same soil of all the different materials above used with the three additional ones just mentioned. The sandy soil was chosen for this series and when peptone (Witte) was used, 0.5 gram of it was added to 50 grams of soil. The peptone contained 14.14 per cent $\mathrm{N}$. The sheep and goat manure (2.13 per cent $\mathrm{N}$ ), owing to its low nitrogen content, was added to the extent of 3 grams per 50 grams of soil, and the phosphatic guano (3.96 per cent $\mathrm{N}$ ) was also added at the rate of 3 grams per 50 grams of soil. The results obtained are recorded in Table VII.

As was to be expected, the very available form of nitrogen in the peptone allows of the production of much larger quantities of ammonia than do the less available forms of the other materials. The fineness of division and easy solubility of the peptone, as well as the form of nitrogen which it contains, doubtless have contributed to the results. The more or less uniform decomposition of it, however, by most of the organisms tested shows peptone to be unsuited, as has been claimed by other investigators, for ammonification studies with pure or mixed cultures when the application of the data obtained, to field conditions, is contemplated. However that may be, Sarcina lutea shows the highest efficiency at ammonifying peptone nitrogen and at least six other organisms approach it rather closely. Relatively speaking, all but two of the organisms tested are efficient ammonifiers of peptone nitrogen. But their position with respect to peptone, as can be seen from Table VII, is no criterion as to their efficiency with respect to the other materials.

One of the interesting facts about the ammonification of the sheep and goat manure by pure cultures is that only one organism showed ammonifying efficiency worthy of the name, and that was B3. megatherium. The other organisms showed a very slight power only of ammonifying the nitrogen in it. Just why this large discrepancy should exist with respect to this manure between B. megalherium and the other organisms still remains 


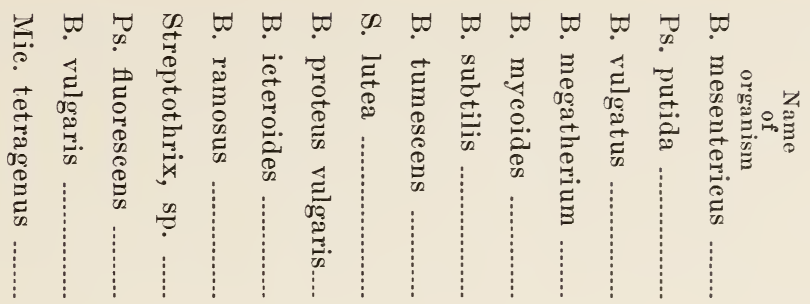

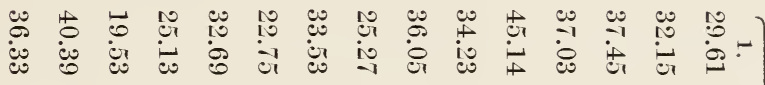

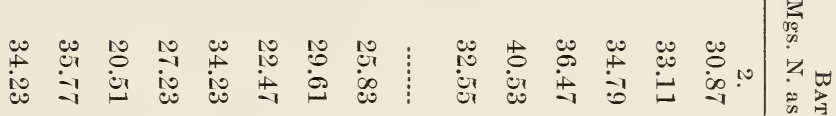
N

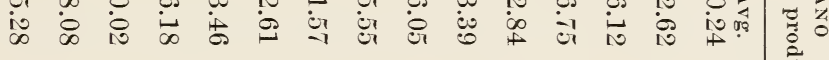
苛

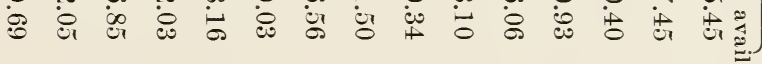

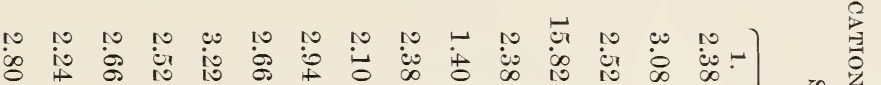

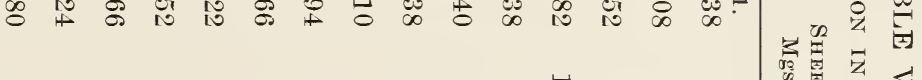

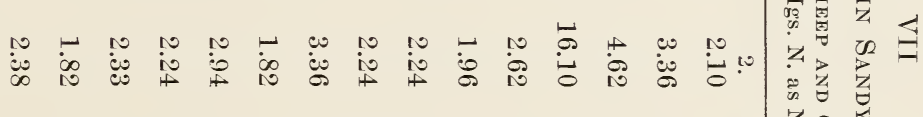

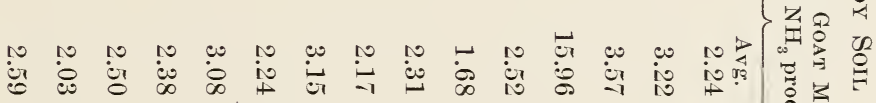

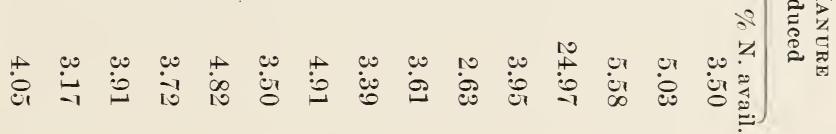

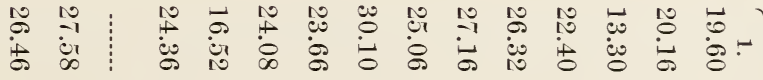

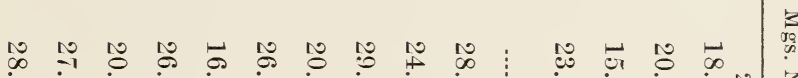
$\dot{0}$ is

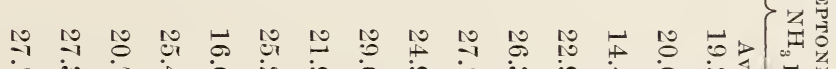

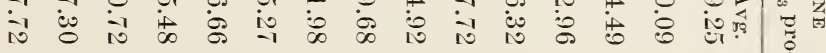

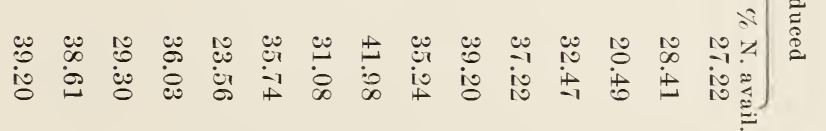


to be explained. If, therefore, the readiness of the transformation of its nitrogen into ammonia by pure cultures of ammonifiers is to be taken as a criterion, sheep and goat manure must be adjudged to contain a relatively unavailable form of nitrogen.

The most amazing evidence portrayed in Table VII is the very high availability of the nitrogen of bat guano, which is a phosphatic guano. While without question the fact of the large amount of the guano used, as well as its low content of nitrogen, preclude an accurate and wholly justifiable comparison of it with the other nitrogenous materials, one cannot help being struck by the large transformation of its nitrogen into ammonia which nearly all of the organisms tested can accomplish. In many ways, the transformation of the nitrogen of bat guano into ammonia resembles that of the transformation of peptone nitrogen. The differences between the ammonifying powers of the different organisms are, however, unquestionably more marked in the case of the bat guano. In its efficiency as an ammonifier of bat guano nitrogen, B. mycoides appears for the first time in all the series studied to be distinctly superior to all the other organisms tested. B. vulgaris easily takes second place. Not far behind, however, and about equal in efficiency, are $B$. megatherium, B. vulgatus, B. tumescens, and Mic. tetragenus. In the third class are B. ramosus, B. subtilis, and Ps. putida, B. proteus vulgaris, and $B$. mesentericus. In the fourth class are Streptothrix, sp., Sarcina lutea, B. icteroides, and Ps. fuorescens.

\section{A Comparison of the Relative Availabilities of the Organic Materials above Employed based on the Percentage of Nitrogen Contained in Them that was Transformed to Ammonia}

Thus far we have been considering only the relative degrees of efficiency as ammonifiers of the different organisms among themselves as respecting a given organic form of nitrogen in a given soil. There is possible, however, a further very interesting study of the data above given as a basis. We refer to the percentage of nitrogen which is transformed in the different materials into ammonia so as to give them a relative rating as to availability as 


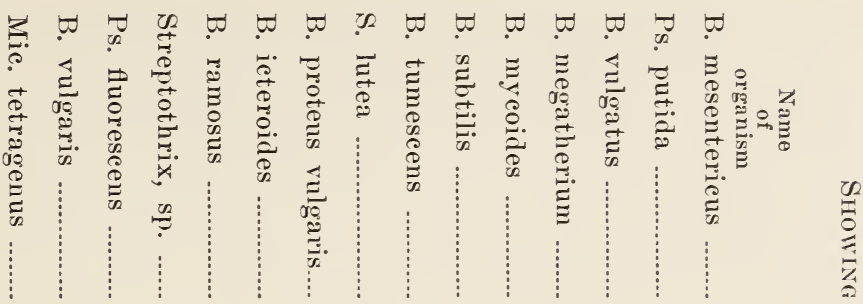

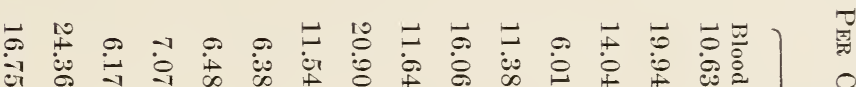

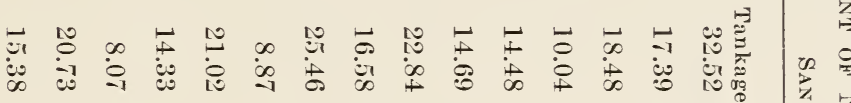

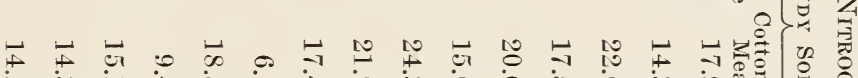

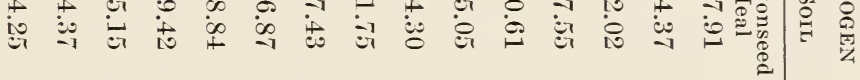

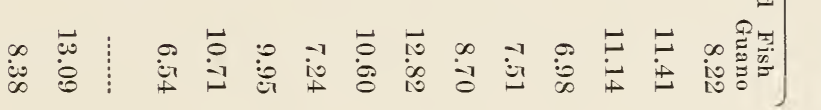

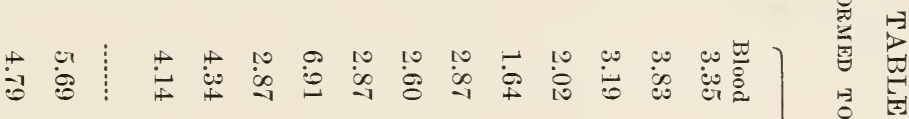

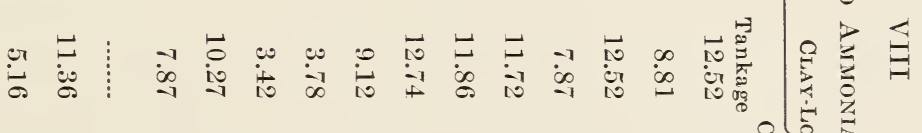

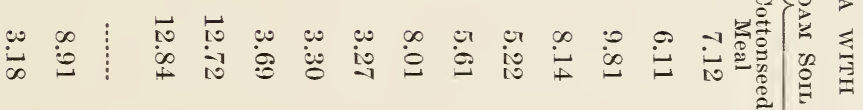

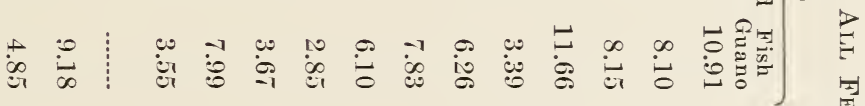

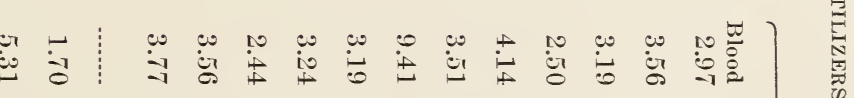

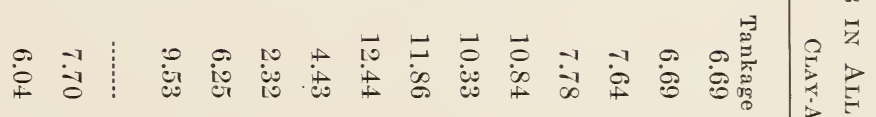

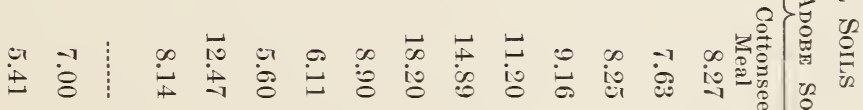

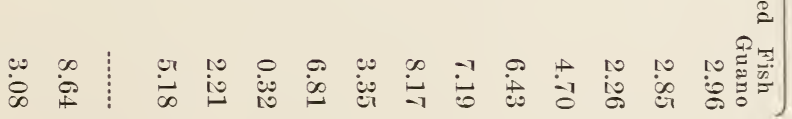


regards the work of pure cultures. The columns on availability of the various tables show a comparison in different soils of all the materials as attacked by the same organisms, and give the percentages of nitrogen in those materials which were transformed to ammonia. In Table VIII all of the columns indicating percentages of nitrogen of different fertilizers made available are brought together from the other tables and one is enabled to compare with much greater ease the different materials on the basis of availability in the same soil and with the same organism and in different soils, with different organisms.

\section{The Sandy Soil}

So far as this soil is concerned, the data in Table VIII indicate clearly the superiority, from the point of view of the availability of its nitrogen, of cottonseed meal to the other organic nitrogenous fertilizers with which it is compared. Not only are the absolute amounts of ammonia produced in most cases larger from cottonseed meal nitrogen than from other forms, but there are more organisms of the fifteen tested which can vigorously ammonify this form of nitrogen. So that to illustrate, there are but five organisms which have shown the power to transform 15 per cent or more of the nitrogen of dried blood into ammonia in the sandy soil. Under similar conditions there are ten organisms which hold such a record for cottonseed meal. Tankage shows itself to be the next important nitrogenous fertilizer to cottonseed meal from the point of view of the availability of its nitrogen. Thus, comparing it with dried blood as above, we find that there are nine organisms which transform 15 per cent or more of the nitrogen of tankage into ammonia. No such high availability is obtained at all in the case of the fish guano.

When we consider these nitrogenous fertilizers from the point of view of the transformation of 10 per cent or more of their nitrogen into ammonia, we find that there are thirteen of the fifteen organisms tested which possess that power as regards cottonseed meal nitrogen and another comes very close to that point. In the case of tankage nitrogen there are thirteen organisms with a similar power. In the case of dried-blood nitrogen 
there are but ten organisms which can accomplish that task, and but seven such in the case of fish-guano nitrogen.

From the point of view of availability by pure cultures therefore in the sandy soil the four nitrogenous fertilizers are to be rated as follows: cottonseed meal, tankage, dried blood, and fish guano. The first two are nearly alike and are far superior to the last two, which are nearly alike, but much more different from each other than the first two.

The greatest efficiency at ammonification manifested by any organism in the sandy soil is that of $B$. mesentericus with tankage nitrogen, which transforms 32.52 per cent of the nitrogen present into ammonia in twelve days. It should be noted in this connection also that absolutely higher amounts of ammonia are produced from tankage nitrogen than from any other form in the sandy soil, even if there are fewer organisms which attack it readily than there are in the case of the cottonseed meal.

\section{The Clay-Loam Soil}

Conditions are evidently entirely different for ammonification in this soil. Not only is the ammonia production very low so far as all the fertilizers are concerned, but they no longer bear to one another the relation which obtained between them in the sandy soil. There are thus but few organisms which possess the power of transforming 10 per cent or more of the total nitrogen in any of the four fertilizers into ammonia in twelve days. In fact, there are none such in the case of the dried blood, only two such each in the cases of cottonseed meal and fish guano, and seven such in the case of the tankage. No organism attains to the production of ammonia equivalent to 13 per cent of the total amount present in the clay-loam soil regardless of the kind of fertilizer at its disposal.

The tankage, however, is superior to the cottonseed meal in the clay loam and distinctly so as above indicated. The cottonseed meal takes second place, the fish guano third place, and the dried blood is by far the poorest. Indeed. no organism was capable of producing an amount of ammonia in excess of 6.91 
per cent of the total amount of dried-blood nitrogen furnished, and that occurred in only one case, all the other organisms producing much less.

\section{The Clay-Adobe Soil}

Some very striking facts become apparent when the availability of the four fertilizers in clay-adobe soil are considered. While on the whole dried-blood nitrogen is only slightly more efficiently transformed into ammonia than in the clay-loam soil, cottonseed meal and tankage, particularly the former, are more vigorously acted on in the clay-adobe soil by most of the organisms. Fish guano, while not markedly so, is none the less superior here again to dried blood.

Again comparing the different fertilizers on the basis of the amounts of their nitrogen transformed into ammonia by the organisms tested, we find that four organisms transform 10 per cent or more of the nitrogen in cottonseed meal into ammonia, a like number accomplish similar results in the case of tankage, and none succeds in that direction in either fish guano or dried blood. While thus cottonseed meal and tankage appear alike, a study of table VIII reveals the superiority of the former in the larger absolute amounts of nitrogen which are transformed there than in the case of the latter.

The first striking fact shown in Table VIII is the marked superiority of the sandy soil as a medium for ammonification by pure cultures. Likewise the added fact of its superiority as a medium for most of the organisms tested must be noted in this connection. The second point of great interest is the surprising fact of the superiority of the clay-adobe soil to the clay-loam soil as a medium for ammonification. From its tenacious nature one would suppose the former type to be a much poorer medium for ammonification than the clay loam and yet it is distinctly superior to the latter as regards tankage and cottonseed meal. As regards fish guano, it is slightly inferior to the clay loam and again as regards the dried blood about equal to the clay loam or possibly slightly superior.

Considering all the data given in Table VIII from all points of view, tankage must be given first place as regards the avail- 
ability of its nitrogen, cottonseed meal easily takes second place and, owing to its superiority in the sandy soil, dried blood takes third place. Considering the superiority of the fish guano to the dried blood in the other soils, however, it is probably fairer to adjudge dried blood and fish guano of equal availability from the point of view of the transformation of their nitrogen into ammonia by pure cultures of ammonifying bacteria.

\section{Generil Discussion}

Several of the facts which have come to light in the investigations above described demand a word of comment with respect to their general significance. First as regards the relative efficiencies at ammonification of the different organisms tested, we find that there is marked variation. Indeed it is difficult to find an organism among the fifteen tested which consistently stands as the best ammonifier regardless of the soil and the ammonifiable material employed. There are, however, one or two organisms which nearly approach such a description. In other words, it appears that, viewing ammonification of organic nitrogen from the standpoint of pure cultures, every organism will do best with a definite combination of soil and organic matter. To be sure there are some organisms of those tested, even though they be in the minority, which are consistently weak ammonifiers. B. icteroides and Ps. fuorescens serve to exemplify such.

That $B$. mycoides is by no means always the most efficient of ammonifying bacteria as has heretofore been believed is clearly indicated above. On the other hand, it does possess and manifest marked superiority in certain cases. Thus, for example, while showing poor or mediocre ammonifying power in different soils with dried blood, tankage and fish guano, it manifests great vigor in the case of cottonseed meal and succeeds in making the record for the percentage of nitrogen transformed in the case of bat guano, in which it transforms to ammonia 36.06 per cent of the nitrogen present. 
Comparing the organisms in any one given soil as a medium we find some interesting facts. In the sandy soil, for example, with dried blood B. vulgaris is the most efficient ammonifier, making available or transforming into ammonia 24.36 per cent of the nitrogen present. With tankage, B. mesentericus shows the highest efficiency, transforming 32.52 per cent of the nitrogen present into ammonia. With cottonseed meal, B. tumescens is paramount, yielding an amount of ammonia equivalent to 24.30 per cent of the amount of nitrogen present. With fish guano, $B$. vulgaris again manifests its superiority over the other organisms by changing 13.09 per cent of the nitrogen present into ammonia. When bat guano is used, B. mycoides stands distinctly superior to all others, as above shown, by transforming 36.06 per cent of the nitrogen present into ammonia. In the case of sheep and goat manure there is but one efficient organism and that is B. megatherium, which transforms 24.97 per cent of the nitrogen present into ammonia. Lastly when peptone is used Sarcina lutea stands pre-eminent, and when all materials are compared, regardless of whether they were used in all soils or not, the lastnamed organism makes the record for availability by transforming 41.98 per cent of the nitrogen present into ammonia. There are thus six organisms out of the fifteen which make records in one and the same soil but with different forms of organic matter. One of the six stands superior in the cases of two nitrogenous materials, namely dried blood and fish guano, and that is B. vulgaris.

Comparing the same organisms with the same nitrogenous materials, above used, except the last three named, in the clayloam soil, we find that with dried blood B. proteus vulgaris is most efficient, transforming 6.9 per cent of the nitrogen present into ammonia. With tankage, $B$. tumescens is pre-eminent and transforms 12.74 per cent of the nitrogen present into ammonia. With cottonseed meal, Streptothrix, sp., is superior, transforming $12.8+$ per cent of the nitrogen present into ammonia; and lastly with fish guano, 3. megatherium is again pre-eminent, transforming 11.66 per cent of the nitrogen present into ammonia. We see again, therefore, that in one and the same soil, with four different materials, four different organisms make records for 
availability. To be sure, two of these organisms have shown themselves superior to all others in the sandy soil but with different materials.

In the case of the clay-adobe soil we find that with dried blood $B$. tumescens stands at the top of the list and transforms 9.41 per cent of the nitrogen present into ammonia. With tankage in the same soil, Sarcina lutea is the most efficient ammonifier and transforms 12.44 per cent of the nitrogen present into ammonia. With cottonseed meal, B. tumescens is again superior to all others and transforms 18.20 per cent of the nitrogen present into ammonia; and finally with fish guano $B$. vulgaris again assumes the ascendency and transforms 8.64 per cent of the nitrogen present into ammonia. $B$. tumescens is very nearly as efficient in this latter case as $B$. vulgaris. We have thus seen that organisms which in all cases have shown their superiority in other soils are also very efficient in the clay-adobe soil.

It is clear, therefore, that only about half of the fifteen organisms tested show greatest efficiency in some soil or with some form of organic matter. Scrutinizing more closely the efficiencies of each of these, we must concede to $B$. tumescens the paramount place among them, for it has stood pre-eminent, in five combinations of soil and fertilizer, out of fifteen, and has in addition been close to first place in several other instances.

Comparing our findings with those of Marchal, the following critical statements must be made. First, that results of solution cultures are no criterion as to results to be obtained in soils. Secondly, that no two forms of organic nitrogen are attacked and ammonified with the same vigor by any one organism. Thirdly, that different soils will modify an organism's power to ammonify any one given form of nitrogen very markedly, so that it may be efficient in one case and feeble in another. Fourthly, that the ammonifying efficiency of organisms is greater in sandy soil, and possibly in others, than in solutions, for we have obtained a transformation of 41.98 per cent of peptone nitrogen and 36.06 per cent of bat guano nitrogen into ammonia by Sarcina lutea and $B$. mycoides respectively in twelve days at temperatures between $27^{\circ} \mathrm{C}$ and $30^{\circ} \mathrm{C}$, while Marchal only obtained similar transformations in thirty days at $30^{\circ} \mathrm{C}$ in albumin solutions. 
Owing to the general distribution of the efficient ammonifying organisms above described in most soils, it is extremely improbable, to judge from our results, that we may look forward to a profitable form of inoculation of soils with ammonifying bacteria. The choice, however, of the form of nitrogenous fertilizer for a soil, which will be most readily made available, when available nitrogen is needed, may indeed be something of much greater practical significance, as our data would appear to indicate. Particularly emphatic are our results in illustrating that, at least so far as pure cultures are concerned, and as also partly shown by J. G. Lipman ${ }^{3}$ and others, with mixed cultures, prevalent ideas with respect to the relative availability of common nitrogenous fertilizers are incorrect. Both tankage and cottonseed meal, and, in some cases, fish guano, show higher availabilities than dried blood, which we have always been in the habit of regarding as the most available of organic nitrogenous fertilizers (based only on vegetation tests).

Nor do we argue too far afield from our subject when we make the remarks just preceding. We recognize fully that availability as measured by ammonification does not necessarily denote availability as measured by nitrification nor by assimilation of nitrogen by plants. We cannot, however, help noting, also, that a persistent preference exists among practical orchardists in this state for tankage as against dried bood and we therefore feel that, judged by other critera, similar conclusions, must be drawn to those adduced from our experiments with pure cultures of ammonifying bacteria.

We have decided, however, to go much further in these experiments and are now prosecuting more elaborate investigations on nitrogen transformation not only to ammonia but also to nitrates. In these studies we shall deal with the soil flora as existing in a large variety of soil types freshly collected from the field for our purposes. Moreover, we shall employ the raw, unsifted fertilizer material just as it is used by the farmer. From these investigations we hope to glean much more evidence which will be of great practical significance, and, like the results above described, also of marked scientific interest. 


\section{Summary}

Results are above given which deal with:

1. The marked differences in ammonifying efficiency of fifteen organisms in pure culture.

2. The soil was used as a medium and three types employed, sandy, clay loam and clay adobe.

3. Four common fertilizers as sources of nitrogen were used, in all soils, and peptone, bat guano, and sheep and goat manure employed only in the sandy soil, besides. The four fertilizers were dried blood, tankage, cottonseed meal and fish guano.

4. The nature of the soil, as well as the nature of the nitrogenous material, markedly modify an organism's ammonifying power.

5. There is no regularity in these variations and they cannot be foretold.

6. While it is difficult to make an exact decision, B. tumescens appears, on the whole, to have been the most efficient organism above tested.

7. The highest efficiency in a single culture with a fertilizer was shown by $B$. mycoides, which transformed in twelve days at $27^{\circ}$ to $30^{\circ} \mathrm{C}, 36.06$ per cent of the nitrogen in bat guano into ammonia.

8. The highest efficiency in a single culture with peptone was shown by Sarcina lutea, which transformed 41.98 per cent of the nitrogen present into ammonia under similar conditions.

9. A comparison of availability of nitrogenous fertilizers with ammonifiability as a criterion, according to our experiments. markedly changes the positions of tankage, fish guano, and cottonseed meal with respect to dried blood, showing them in most or in many cases to be superior to the latter.

10. One half of the number of organisms tested is far superior to the other half in ammonifying ability.

11. Interesting comparisons with Marchal's work are made.

12. B. icteroides has shown itself throughout to possess but little ammonifying efficiency. 
13. Experiments are following those above described to make the latter more complete. Elaborate tests are being made with many soil types using the original soil's mixed flora from freshly collected samples in the field. Not only ammonifying powers of these mixed flora in the different soil types will be studied, but also the corresponding nitrifying powers. A large variety of nitrogenous fertilizers as employed in practice will be tested here.

REFERENCES OF MORE OR LESS DIRECT PERTINENCE

1 Bull. Acad. Roy. Soc. Belg., 3 ser., vol. 25, p. 727.

2 Voorhees, Fertilizers, Macmillan Co., 1898.

3 N. J. Sta. Bulletin, no. 246.

4 Ann. Sci. Agron., vol. 19, p. 209.

5 Rpt. Del. Exp. Sta., 1899, p. 76.

6 Cent. für Bakt., $2^{\text {te }}$ Abt., vol. 20, p. 322.

7 Ibid., vol. 15, p. 433.

8 Ibid., vol. 29, p. 238.

9 Ibid., vol. 31, p. 49. 